\title{
Palonosetron in the management of chemotherapy- induced nausea and vomiting in patients receiving multiple-day chemotherapy
}

This article was published in the following Dove Press journal:

Cancer Management and Research

5 September 2014

Number of times this article has been viewed

\author{
Mary Lou Affronti' \\ Joseph Bubalo² \\ 'Duke University Medical Center, \\ Durham, NC, ${ }^{2}$ Oregon Health and \\ Science University Hospital and \\ Clinics, Portland, OR, USA
}

Correspondence: Mary Lou Affronti Department of Surgery and Duke School of Nursing, Clinical Associate Faculty, Preston Robert Tisch Brain Tumor Center, Duke University Medical Center, 047 Baker House Trent Drive, DUMC Box 3624, Durham, NC 277I0, USA $\mathrm{Tel}+\mathrm{I} 9196846239$

$\mathrm{Fax}+19196811697$

Email mary.affronti@duke.edu

\begin{abstract}
Prevention of chemotherapy-induced nausea and vomiting (CINV) is a key component of treatment for patients with cancer. Guidelines are available to assist prescribers in the management of CINV associated with single-day chemotherapy regimens. However, currently there are no clear guidelines for management of CINV in patients receiving multiple-day chemotherapy regimens. Serotonin $\left(5-\mathrm{HT}_{3}\right)$ receptor antagonists are a mainstay in preventing CINV, and palonosetron, given its longer half-life and duration of action relative to other 5- $\mathrm{HT}_{3}$ receptor antagonists, may be a useful option for managing CINV in multiple-day chemotherapy. Here we provide an overview of CINV and CINV treatment options, with a focus on palonosetron. We describe existing challenges in managing CINV, and discuss two patients receiving multiple-day chemotherapy, in whom CINV was managed successfully with palonosetron.
\end{abstract}

Keywords: chemotherapy-induced nausea and vomiting, palonosetron, multiple-day chemotherapy, $5-\mathrm{HT}_{3}$ receptor antagonist

\section{Introduction}

Prevention and management of chemotherapy-induced nausea and vomiting (CINV) is an important consideration in patients receiving treatment for cancer. ${ }^{1}$ Patients rank nausea and vomiting as one of the most distressing side effects of chemotherapy, ${ }^{2-5}$ although the incidence of CINV may be generally underestimated in clinical practice. ${ }^{6,7}$ CINV negatively affects quality of life and interferes with daily functioning. ${ }^{8,9}$ In addition to effects on quality of life and functional impairment, CINV can lead to medical complications, including anorexia, nutrient depletion, and metabolic disturbances, or may lead to noncompliance or premature discontinuation of anticancer therapy. ${ }^{10,11}$ In this paper, we provide an overview of CINV and antiemetics, with a focus on palonosetron. We also discuss challenges and unmet needs in prevention of CINV, including its prophylaxis in patients receiving multiple-day chemotherapy, and describe two patient cases that illustrate the use of palonosetron in the setting of multiple-day chemotherapy.

\section{Overview of CINV and prevention with antiemetics}

The risk of CINV varies depending on the chemotherapy regimen and on other factors. Chemotherapy can be classified by the associated emetic risk (Table 1) (10,12-14 $^{1}$ as high risk (highly emetic chemotherapy [HEC], >90\%), moderate risk (moderately emetic chemotherapy [MEC], 30\%-90\%); low risk (10\%-30\%); or minimal risk $<10 \%) .{ }^{10}$ Patient-related variables that influence the risk for CINV include age (younger patients tend to experience more CINV) and sex (women experience more 
Table I Emetogenic risk of single chemotherapeutic agents

\begin{tabular}{|c|c|c|}
\hline \multicolumn{2}{|l|}{ Intravenous } & Oral \\
\hline \multicolumn{3}{|c|}{ High (emesis risk $>90 \%$ without antiemetics) } \\
\hline Carmustine & Dacarbazine & Hexamethylmelamine \\
\hline Cisplatin & Mechlorethamine & Procarbazine \\
\hline Cyclophosphamide & \multirow{2}{*}{\multicolumn{2}{|c|}{ Streptozocin }} \\
\hline$\left(\geq 1,500 \mathrm{mg} / \mathrm{m}^{2}\right)$ & & \\
\hline \multicolumn{3}{|c|}{ Moderate (emesis risk 30\%-90\% without antiemetics) } \\
\hline Alemtuzumab & Daunorubicin & Cyclophosphamide \\
\hline Azacitidine & Doxorubicin & Imatinib \\
\hline Bendamustine & Epirubicin & Temozolomide \\
\hline Carboplatin & Idarubicin & Vinorelbine \\
\hline Clofarabine & Ifosfamide & \\
\hline Cyclophosphamide & Irinotecan & \\
\hline \multicolumn{3}{|l|}{$\left(<\mathrm{I}, 500 \mathrm{mg} / \mathrm{m}^{2}\right)$} \\
\hline Cytarabine $\left(>1,000 \mathrm{mg} / \mathrm{m}^{2}\right)$ & \multicolumn{2}{|l|}{ Oxaliplatin } \\
\hline \multicolumn{3}{|c|}{ Low (emesis risk $10 \%-30 \%$ without antiemetics) } \\
\hline Bortezomib & Ixabepilone & Capecitabine \\
\hline Cabazitaxel & Methotrexate & Etoposide \\
\hline Catumaxomab & Mitomycin & Everolimus \\
\hline Cetuximab & Mitoxantrone & Fludarabine \\
\hline Cytarabine $\left(\leq 1,000 \mathrm{mg} / \mathrm{m}^{2}\right)$ & Paclitaxel & Lapatinib \\
\hline Docetaxel & Panitumumab & Lenalidomide \\
\hline Doxorubicin (liposomal) & Pemetrexed & Tegafur uracil \\
\hline Etoposide & Temsirolimus & Thalidomide \\
\hline 5-Fluorouracil & Topotecan & \\
\hline Gemcitabine & Trastuzumab & \\
\hline \multicolumn{3}{|c|}{ Minimal (emesis risk $<10 \%$ without antiemetics) } \\
\hline Bevacizumab & Fludarabine & Chlorambucil \\
\hline Bleomycin & Rituximab & Erlotinib \\
\hline Busulfan & Vinblastine & Gefitinib \\
\hline \multirow{7}{*}{$\begin{array}{l}\text { Cladribine } \\
\text { (2-chlorodeoxyadenosine) }\end{array}$} & Vincristine & Hydroxyurea \\
\hline & & \\
\hline & Vinorelbine & L-phenylalanine \\
\hline & & mustard \\
\hline & & Methotrexate \\
\hline & & Sorafenib \\
\hline & & 6-Thioguanine \\
\hline
\end{tabular}

Notes: Adapted from Grunberg SM, Warr D, Gralla RJ, et al. Evaluation of new antiemetic agents and definition of antineoplastic agent emetogenicity-state of the art, Support Care Cancer, 19(Suppl I), 201I: S43-S47, with kind permission from Springer Science and Business Media. ${ }^{12}$ Reprinted from Basch E, Prestrud AA, Hesketh PJ, et al. J Clin Oncol, 29(3I), 20I I: I489-1498, with permission. (C) 20II American Society of Clinical Oncology. All rights reserved. ${ }^{14}$

CINV than men). ${ }^{9} \mathrm{CINV}$ is frequently classified in a biphasic manner, ie, acute CINV occurs within the first 24 hours after chemotherapy and delayed CINV occurs more than 24 hours after chemotherapy. ${ }^{15}$ Delayed CINV is more common with cisplatin, carboplatin, cyclophosphamide, and/or doxorubicin. ${ }^{10}$

The introduction and development of novel treatments has significantly improved clinicians' ability to prevent and manage CINV, and the effectiveness of antiemetic therapy may allow for more aggressive chemotherapy on an outpatient basis. The mainstays of CINV prophylaxis include serotonin $\left(5-\mathrm{HT}_{3}\right)$ receptor antagonists (RAs) and neurokinin $1\left(\mathrm{NK}_{1}\right)$ RAs. ${ }^{10}$ These agents block receptors for serotonin and substance $\mathrm{P}$, located in the gastrointestinal tract and central nervous system, respectively. Serotonin and substance $P$ are the two key neurotransmitters involved in the pathophysiology of vomiting. ${ }^{16}$

The 5- $\mathrm{HT}_{3}$ RAs approved in the USA include dolasetron, granisetron, ondansetron, and palonosetron. Certain 5- $\mathrm{HT}_{3}$ RAs (ondansetron, granisetron, dolasetron) have comparable efficacy in controlling acute nausea and/or vomiting (in the first 24 hours after chemotherapy) associated with HEC or MEC, ${ }^{16,17}$ but have demonstrated limited benefit for delayed CINV. ${ }^{18-20}$ In contrast, palonosetron has demonstrated benefit in controlling both acute and delayed CINV. ${ }^{21-24}$

NK 1 RAs approved by the US Food and Drug Administration are aprepitant and its prodrug, fosaprepitant, with rolapitant and netupitant currently in clinical trials. ${ }^{16}$ The addition of $\mathrm{NK}_{1}$ RAs to standard antiemetic regimens has been shown to improve control of acute and delayed CINV associated with HEC or MEC when compared with standard two-drug regimens. ${ }^{25-28}$

Practice guidelines (from the National Comprehensive Cancer Network [NCCN], Multinational Association of Supportive Care in Cancer/European Society for Medical Oncology [MASCC/ESMO], and American Society of Clinical Oncology [ASCO]) recommend a combination of antiemetic agents for the prevention of CINV with HEC, specifically "triple therapy" with an $\mathrm{NK}_{1} \mathrm{RA}$, a $5-\mathrm{HT}_{3} \mathrm{RA}$, and dexamethasone. ${ }^{10,13,14}$ Guidelines for MEC generally include a $5-\mathrm{HT}_{3} \mathrm{RA}$ and dexamethasone ( \pm an $\left.\mathrm{NK}_{1} \mathrm{RA}\right)$ on day 1 , followed by monotherapy with a $5-\mathrm{HT}_{3} \mathrm{RA}$ or dexamethasone (or $\mathrm{NK}_{1} \mathrm{RA}+$ dexamethasone) on days 2 and 3. ${ }^{10,13,14}$ Guidelines from the NCCN for HEC or MEC include olanzapine as an alternative to an $\mathrm{NK}_{1} \mathrm{RA},{ }^{10}$ and olanzapine is included as a potential adjunctive treatment in the ASCO guidelines. ${ }^{14}$ Other adjunctive treatments may include lorazepam, ${ }^{10,14} \mathrm{H} 2$ blockers, ${ }^{10}$ and diphenhydramine. ${ }^{14}$

\section{Unmet needs/challenges in CINV prophylaxis}

Despite the development of more effective antiemetic regimens, implementation of guideline-recommended CINV prophylaxis in clinical practice remains suboptimal. ${ }^{29}$ A prospective, observational study conducted in Europe by Aapro et al that included 991 patients receiving single-day HEC or MEC found that guideline-consistent CINV prophylaxis was used for $55 \%$ and $46 \%$ of patients in the acute and delayed phases, respectively, and in only $29 \%$ overall. ${ }^{15}$ They also showed a significant difference in complete response rates for patients receiving guideline-consistent CINV prophylaxis versus those who did not (odds ratio 1.43, 95\% confidence 
interval 1.04-1.97, $P=0.027) .{ }^{15}$ Gilmore et al conducted a similar study in the USA and reported similar findings. In a prospective, observational study of 1,295 patients receiving single-day HEC or MEC, the overall prevalence of guidelineconsistent CINV prophylaxis was $57.3 \%$, with a significantly higher incidence of no CINV among patients who received guideline-consistent CINV prophylaxis compared with those who did not (53.4\% versus $43.8 \%, P<0.001$; odds ratio 1.31 , $95 \%$ confidence interval $1.07-1.69, P=0.037) .{ }^{30}$

The negative effects of CINV on quality of life are particularly associated with delayed CINV. ${ }^{8}$ Impairment of quality of life due to delayed CINV can affect patients who receive antiemetic therapy and do not experience acute CINV; delayed nausea may have a stronger negative effect than vomiting. ${ }^{31}$ With the use of current antiemetic regimens, delayed CINV may be more common than acute CINV. For example, a recent study of 277 patients in clinical practice in the Netherlands reported rates of delayed nausea and vomiting during the first cycle of HEC or MEC ( $68 \%$ and 23\%, respectively) that were higher than rates of acute nausea and vomiting (39\% and $12 \%$, respectively). ${ }^{9}$ This finding is consistent with previous observations that delayed CINV is generally more difficult to control than acute CINV with many 5-HT RAs. $^{18-20}$ The observation that agents including the $\mathrm{NK}_{1} \mathrm{RAs}$ and palonosetron have improved efficacy in the delayed phase relative to other 5- $\mathrm{HT}_{3}$ RAs suggests that different mechanisms may be involved in the development of acute versus delayed CINV, with acute CINV mediated by $5-\mathrm{HT}_{3}$ and delayed CINV mediated by substance P. ${ }^{32}$ Although physicians are aware of the challenge of delayed CINV and the availability of effective management strategies, it may be difficult to implement these in practice. ${ }^{33}$ Financial issues, provider barriers, and patient factors (eg, adherence and under-reporting of CINV) have been cited as obstacles to effective CINV management. ${ }^{34,35}$

Management of CINV in patients receiving multiple-day chemotherapy presents additional challenges over those seen in single-day chemotherapy regimens. Patients are at risk for acute CINV each day of chemotherapy, with a period of risk for delayed emesis overlapping with subsequent days of therapy and persisting after its completion. The risk for acute and delayed CINV depends partly on the emetogenic potential of the specific chemotherapy administered. ${ }^{10}$ Since the risk for acute and delayed nausea and emesis overlaps after the first day of chemotherapy, ${ }^{10} \mathrm{CINV}$ with multiple-day chemotherapy may be more difficult to manage than CINV with single-day chemotherapy. Further, because the patterns and mechanisms of CINV from multiple-day chemotherapy may differ from those associated with single-day chemotherapy, the efficacy of antiemetics as observed in studies of single-day chemotherapy may not be applicable. ${ }^{36}$ Data from clinical trials, particularly double-blind, placebo-controlled trials, are somewhat limited. ${ }^{37}$ Early studies in patients receiving 5-day cisplatin-based regimens demonstrated better emetic control with 5- $\mathrm{HT}_{3} \mathrm{RAs}$ (granisetron or ondansetron) over metoclopramide, ${ }^{37-41}$ and the combination of a 5- $\mathrm{HT}_{3}$ RA (granisetron or dolasetron) plus a corticosteroid or the combination of a $5-\mathrm{HT}_{3} \mathrm{RA}$ (ondansetron) plus a corticosteroid and chlorpromazine ${ }^{42}$ was more effective than a 5-HT 3 RA alone..$^{37,43,44}$ Further randomized, doubleblind, comparative studies have shown similar efficacy for $5-\mathrm{HT}_{3}$ RAs (granisetron or ondansetron alone ${ }^{45}$ or granisetron, ondansetron, or tropisetron [plus dexamethasone] ${ }^{46}$ ) in patients receiving cisplatin ( \pm doxorubicin) and/or ifosfamide. In these studies, antiemetic therapy was administered throughout the chemotherapy cycles; however, efficacy generally declined over the course of treatment. ${ }^{45,46}$ Open-label $^{47-49}$ and observationa ${ }^{50}$ studies have shown the efficacy of palonosetron in patients receiving various multiple-day chemotherapy regimens. Data from nonrandomized studies ${ }^{51-54}$ and randomized controlled trials ${ }^{55}$ support the use of triple antiemetic regimens (ie, $5-\mathrm{HT}_{3} \mathrm{RA}+$ corticosteroid $+\mathrm{NK}_{1} \mathrm{RA}$ ) for multiple-day chemotherapy CINV prophylaxis. However, given the considerable variation in multiple-day chemotherapy regimens, a true standard of care or optimal antiemetic regimen has not been established.

Practice guidelines for CINV prophylaxis in patients receiving multiple-day chemotherapy have been developed based on available data. ASCO guidelines recommend that appropriate antiemetic therapy for the type of chemotherapy given should be administered on each day of chemotherapy and for 2 days after, if appropriate. They suggest, based on limited data, that patients receiving 5-day cisplatin regimens receive a $5-\mathrm{HT}_{3} \mathrm{RA}$ in combination with dexamethasone and aprepitant. ${ }^{14} \mathrm{NCCN}$ guidelines recommend use of daily dexamethasone during multiple-day chemotherapy and for 2-3 days after chemotherapy for regimens likely to cause delayed CINV. In addition, a 5- $\mathrm{HT}_{3}$ RA should be administered before each dose of chemotherapy, with the frequency of administration based on the specific $5-\mathrm{HT}_{3}$ RA used; a single dose of intravenous palonosetron at the start of a 3-day chemotherapy regimen may be sufficient instead of multiple daily doses of other oral or intravenous $5-\mathrm{HT}_{3} \mathrm{RAs}$. Finally, an $\mathrm{NK}_{1}$ RA may be used for regimens associated with a significant risk of delayed CINV. ${ }^{10}$

\section{Why the interest in palonosetron versus other $5-\mathrm{HT}_{3}$ antagonists?}

Palonosetron is a $5-\mathrm{HT}_{3} \mathrm{RA}$ indicated to control acute and delayed nausea and vomiting associated with initial or 
repeated courses of MEC and for the prevention of acute nausea and vomiting associated with initial and repeat courses of HEC. ${ }^{56}$

The observed differences in efficacy in the delayed phase for palonosetron versus other $5-\mathrm{HT}_{3}$ RAs may be partly explained by the drug's pharmacology. ${ }^{57}$ Palonosetron has a longer half-life and greater $5-\mathrm{HT}_{3}$ receptor binding affinity compared with other $5-\mathrm{HT}_{3}$ RAs. ${ }^{58}$ Palonosetron has a unique binding profile (allosteric binding and positive cooperativity) that differs from that of other $5-\mathrm{HT}_{3} \mathrm{RAs}^{59}$ and triggers receptor internalization, inducing prolonged inhibition of receptor functioning. ${ }^{60}$ Finally, palonosetron inhibits crosstalk between $5-\mathrm{HT}_{3}$ and $\mathrm{NK}_{1}$ signaling pathways. ${ }^{61}$

Multiple practice guidelines cite palonosetron as the preferred 5- $\mathrm{HT}_{3}$ RA for single-day MEC, ${ }^{10,13,14}$ and one suggests it may be preferred for HEC CINV prophylaxis. ${ }^{10}$ These recommendations are supported by evidence from randomized controlled trials and meta-analyses that showed better control of delayed emesis and delayed nausea compared with other $5-\mathrm{HT}_{3}$ RAs. $^{62-65}$ However, there is disagreement by some regarding these recommendations due to other considerations, such as limitations of the clinical trials on which the recommendations are based and cost. ${ }^{66,67}$

\section{CINV prophylaxis with}

\section{palonosetron in patients receiving multiple-day chemotherapy: translating data into practice}

The following clinical case studies help illustrate the use of palonosetron in clinical practice and show the application of published data and treatment guidelines in clinical practice, with a focus on use of palonosetron.

\section{Clinical case I : malignant glioma}

The following case study presents a patient with a malignant glioma who received standard therapy composed of 6 weeks of radiation with concurrent moderately emetic metronomic oral temozolomide $75 \mathrm{mg} / \mathrm{m}^{2} /$ day followed by multiple-day adjuvant chemotherapy with oral temozolomide $150 \mathrm{mg} / \mathrm{m}^{2} /$ day for days $1-5$ administered every 28 days for a total of 12 cycles.

\section{History of brain tumor diagnosis}

A 58-year-old Caucasian woman presented after 3 months of severe headaches, decreased short-term memory, and difficulty following directions. Computed tomography and magnetic resonance imaging (MRI) of the brain revealed a large, unresectable, nonenhancing $\mathrm{T} 2$ hyperintense butterfly lesion in the right posterior corpus callosum. She underwent an MRI-guided stereotactic brain biopsy at a major academic brain tumor center. Pathology findings revealed an anaplastic gemistocytic astrocytoma (World Health Organization grade III).

\section{Glioma treatment recommendations}

As recommended by the neuro-oncology team, the patient received standard malignant glioma therapy of 59.4 Gy of radiation over 33 fractions with concurrent oral temozolomide at $75 \mathrm{mg} / \mathrm{m}^{2} /$ day for 6 weeks. ${ }^{68}$ Before radiation, the patient was prescribed oral dexamethasone $2 \mathrm{mg}$ twice daily for headaches related to cerebral edema and in anticipation of radiation-induced cerebral swelling.

\section{Risk factors for nausea and vomiting}

The patient's risk factors for radiation-induced nausea and vomiting (RINV) were assessed in the clinic before initiation of chemoradiation. The patient had a history of diverticulitis, anxiety, and postoperative nausea related to the narcotics administered for her persistent headaches. Other significant risk factors for nausea and vomiting included female sex and low alcohol use (less than half an ounce daily). Less significant risk factors were a history of motion sickness and emesis during pregnancy. Although risk prediction models are in development to assist health care providers in identifying patients more likely to experience RINV or $\mathrm{CINV}$, the primary risk factor for $\mathrm{C} / \mathrm{RINV}$ is the emetogenic potential of the regimen. ${ }^{1}$

\section{Antiemetic treatment recommendations for RINV}

The neuro-oncology team prescribed an evidenced-based antiemetic to prevent RINV. Prophylactic antiemetic regimens for RINV are based on the site of radiation (eg, brain irradiation is associated with a high RINV risk) and whether the radiation is combined with chemotherapy. ${ }^{10}$ A systematic review and meta-analysis suggest that $5-\mathrm{HT}_{3}$ RAs are the preferred agents for preventing RINV. ${ }^{69,70}$ The NCCN, MASCC/ESMO, and ASCO antiemetic guidelines recommend the combination of palonosetron ("preferred, long-acting" 5-HT 3 RA) and dexamethasone for prevention of both acute and delayed CINV in MEC such as temozolomide, ${ }^{10,13,14}$ with one guideline suggesting it for HEC CINV prophylaxis. ${ }^{10}$

As with many patients with glioma, this patient had cognitive deficits (inability to follow and remember instructions); thus, instead of relying on her to self-administer an 
oral antiemetic, it was planned for this patient to receive intravenous palonosetron $0.25 \mathrm{mg}$ once every 7 days for each week of radiation and temozolomide therapy. Overall, she tolerated radiation and concurrent temozolomide well, with a complete C/RINV response (no emesis or use of rescue medication) for weeks 1 through 5. Although the patient never experienced an emetic episode throughout chemoradiation, she developed grade I nausea from the anticipated cumulative effects of therapy and required a rescue antiemetic twice during the last week of radiation. Quality of life survey results indicated that CINV did not significantly impact her daily functioning (eg, life enjoyment, social life, sleep).

\section{CINV antiemetic treatment recommendations}

After completing radiation and concurrent temozolomide, the patient's MRI demonstrated only slight linear enhancement and continued to show a stable T2 signal mass expanding into the splenium of the corpus callosum. The mass extended within the periventricular and deep white matter in the bilateral parietal-occipital lobes. However, there was no mass effect or cerebral edema. Thus, given her encouraging (ie, stable) post-radiation MRI results, the patient began a trial of standard adjuvant multiple-day chemotherapy with moderately emetic oral temozolomide at $150 \mathrm{mg} / \mathrm{m}^{2} /$ day for days $1-5$ administered every 28 days for 12 cycles. $^{68}$

Preventing CINV in multiple-day chemotherapy is difficult, because the cumulative effects can increase the emetogenic potential. No standard evidence-based antiemetic treatment exists for the multiple-day chemotherapy regimen; however, the NCCN suggests dexamethasone in combination with a $5-\mathrm{HT}_{3} \mathrm{RA}$ in patients receiving a multiple-day MEC regimen. ${ }^{10}$ Therefore, for this particular phase of oral chemotherapy, a less expensive $5-\mathrm{HT}_{3} \mathrm{RA}$ agent, the granisetron transdermal patch (GTP), was initiated for the management of CINV. This selection also limited monthly intravenous injections and was expected to have less potential for nonadherence due to the patient's cognitive deficits.

To provide the patient with control for breakthrough nausea and vomiting, oral lorazepam $0.5 \mathrm{mg}$ was also prescribed, and to be administered every 4-6 hours as needed (prochlorperazine and metoclopramide are avoided in patients with glioma due to their side effects, eg, akathisia). If she continued to have difficulty, the neuro-oncology provider additionally suggested adding dronabinol to her regimen. It is also important to note that given the absence of cerebral swelling, the patient was to begin a steroid taper in 1 month after her first cycle of temozolomide. She was directed to decrease oral dexamethasone from $2 \mathrm{mg}$ twice daily by $0.5 \mathrm{mg}$ every 2 weeks thereafter.

Twenty-four hours before the first dose of temozolomide, the patient applied the GTP and self-administered one dose of oral lorazepam 30 minutes before temozolomide. Unfortunately, after the first dose, the patient "vomited all night" and eventually presented to the emergency room where she received intravenous metoclopramide and fluids, with amelioration of symptoms. However, 2 days after completing temozolomide, the patient continued to be nauseated, which prevented compliance with additional medications.

This case emphasizes that poor CINV management can reduce a patient's quality of life ${ }^{71}$ while increasing caregiver burden. In addition, poorly controlled CINV can be costly. Tina Shih et $\mathrm{al}^{72}$ demonstrated that despite the use of a $5-\mathrm{HT}_{3}$ RA, uncontrolled CINV can pose a $\$ 1,383$ monthly increase in direct medical costs compared with controlled CINV $(P<0.0001)$. Palonosetron has also been found to reduce extreme CINV events (eg, hospitalizations and emergency room and outpatient visits due to CINV) and costs by up to $76 \%$ compared with other $5-\mathrm{HT}_{3}$ RAs, and has reduced staff management work time by approximately 4 months. ${ }^{71}$ Although the GTP was convenient for the patient in this case, there is limited evidence to support the efficacy of the GTP for multiple-day MEC, ${ }^{73}$ and no published data are available evaluating GTP specifically in patients undergoing treatment for glioma. Further, the NCCN suggests that a single dose of palonosetron may be effective in preventing CINV for a multiple-day regimen, although this finding is also based on limited evidence. ${ }^{10}$

Subsequently, based on encouraging evidence from Rozzi et al, ${ }^{48}$ and the patient's positive prior experience with palonosetron, her antiemetic regimen was changed. She was scheduled to receive palonosetron in the clinic setting before each monthly (28-day) temozolomide cycle for a total of eleven remaining cycles. The patient reported that palonosetron significantly improved her nausea and resolved her vomiting for the eleven remaining cycles. She required lorazepam for anxiety and nausea once or twice per cycle for only two of her remaining cycles. Otherwise, the patient had no chemotherapy-induced vomiting on palonosetron when administered on day 1 of chemotherapy in combination with a lower dose of dexamethasone (for cerebral swelling). She eventually tapered off dexamethasone for cerebral swelling during cycle 6 .

Nausea in this case and in most cases was less controlled. The literature shows that nausea may not be a presymptom of vomiting or even relieved by the same 
prophylactic antiemetic, ${ }^{74}$ emphasizing that nausea is subjective. This case finding is supported by data suggesting that nausea is more associated with anorexia than with vomiting, ${ }^{75}$ as such, management of nausea by nonpharmacological and nutritional interventions may be needed. Although the nausea and vomiting constructs historically have been combined into one dichotomous end point, future studies should aim to better understand these different phenomena by evaluating these two end points separately. ${ }^{74}$

\section{Clinical case 2: testicular cancer}

The following case study presents a patient with testicular cancer who received standard chemotherapy with bleomycin, etoposide, and cisplatin.

\section{History of illness}

An 18-year-old Caucasian man with metastatic, nonseminomatous testicular cancer was admitted to the hospital for rehydration, treatment of nausea and emesis, and evaluation of weakness on day 9 of the first cycle of BEP chemotherapy, ie, bleomycin (20 units intravenously on days 1,8 , and 15$)$, etoposide $\left(100 \mathrm{mg} / \mathrm{m}^{2}\right.$ intravenously on days $1-5)$, and cisplatin $\left(20 \mathrm{mg} / \mathrm{m}^{2}\right.$ intravenously on days 1-5).

\section{Prior antiemetic regimen}

The patient received oral dexamethasone $20 \mathrm{mg}$ daily and oral ondansetron $24 \mathrm{mg}$ daily during chemotherapy. On discharge, he was given oral dexamethasone (4 mg twice daily for 4 days) and oral metoclopramide (30 mg every 6 hours for 4 days), to be completed on day 9 (ie, the day he presented to the hospital). He was also prescribed oral lorazepam $1 \mathrm{mg}$ every 4 hours as needed for nausea/ anxiety.

Despite prescribing of and adhering to antiemetics per guidelines, the patient had not experienced sufficient control of CINV to maintain nutrition and hydration outside of the hospital and was subsequently admitted for acute management. An additional concern of the patient and his family was the number of days of school missed, not only due to emesis, which started on the afternoon on day 8 , but also because of the considerable sedation he experienced from the regimen of metoclopramide and lorazepam he had used on days 6-7, which left him able to function only minimally at school. Impaired functioning associated with CINV is well established, ${ }^{8,9}$ and this patient's experience highlights the need to consider potential adverse events when selecting an antiemetic treatment regimen.

\section{Acute management of nausea/ vomiting/weakness}

Over the next 3 days, the patient responded to a combination of intravenous fluids, dexamethasone, prochlorperazine, lorazepam, and dronabinol. By day 3, he was ingesting adequate fluids and nutrition to be discharged from the hospital.

\section{Considerations and selection of alternate antiemetic regimens}

Alternate regimens considered for cycle 2 were the addition of olanzapine, changing to another antagonist backbone, including an alternate $5-\mathrm{HT}_{3} \mathrm{RA}$ such as a GTP or substitution of palonosetron on days 1,3 , and 5 of chemotherapy, and the addition of aprepitant to the regimen. Olanzapine has demonstrated efficacy in combination with a 5- $\mathrm{HT}_{3} \mathrm{RA}$ and corticosteroid in CINV prophylaxis for single-day HEC or MEC. ${ }^{76,77}$ As noted above, there is some evidence supporting the efficacy of the GTP in multiple-day chemotherapy. ${ }^{73,78}$ However, data are not available concerning its use specifically in patients with testicular cancer. A study of 41 patients undergoing BEP chemotherapy for testicular cancer demonstrated the efficacy of a regimen of palonosetron on days 1,3, and 5, plus dexamethasone.$^{47} \mathrm{~A}$ placebo-controlled, randomized controlled trial showed that addition of aprepitant to a 5-HT ${ }_{3}$ RA and dexamethasone improved CINV prophylaxis in patients with germ cell cancers treated with cisplatin-based chemotherapy. ${ }^{55}$

After considering the risk for adverse effects, drug interactions, and convenience of different agents in a patient with an interest in maintaining as much educational continuity as possible, it was decided to use the day 1, 3, and 5 palonosetron schedule with a dexamethasone taper that extended through day 9 of his 21-day chemotherapy plan.

\section{Outcome}

This plan began with cycle 2, and the patient achieved significantly improved control of his CINV. During cycle 2, he had no emetic events and only mild nausea, which he was able to manage successfully with low-dose ( $2.5-5 \mathrm{mg} / \mathrm{dose})$ dronabinol. He missed no days of school other than during the actual infusion days. This antiemetic regimen was maintained successfully through cycles 3 and 4 of his planned 12-week chemotherapy course.

\section{Conclusion}

Evidence-based guidelines give limited options for antiemetics to prevent CINV in patients undergoing multiple-day chemotherapy. The patient with malignant 
glioma presented above, who received standard-of-care, multiple-day chemotherapy in the radiation and adjuvant treatment settings, experienced amelioration of CINV when given a single dose of palonosetron (with dexamethasone) before multiple doses of temozolomide in these settings. The patient with metastatic testicular cancer, also presented above, benefited from multiple doses of palonosetron throughout multiple-day cisplatin-based chemotherapy, not only in controlling CINV, but in improving quality of life. Both cases show that dosing palonosetron based upon its pharmacologic properties could be useful in controlling CINV in multiple cycles of multiple-day chemotherapy. Although high-grade evidence supports the use of palonosetron in the single-dose chemotherapy setting, ${ }^{10,13,14}$ and small studies demonstrate some effectiveness during adjuvant multiple-day chemotherapy for glioma ${ }^{48}$ or during multiple-day treatment for testicular cancer, ${ }^{47}$ randomized trials should be conducted to determine its efficacy versus that of other antiemetics and the most effective dose and frequency.

\section{Acknowledgment}

The authors acknowledge Sherri D Jones of MedVal Scientific Information Services, LLC, for providing medical writing and editorial assistance.

\section{Author contributions}

Both authors contributed equally to this manuscript, each contributed a case from their practice for the case report, and each was involved in drafting or critically revising the manuscript. Both authors reviewed the final manuscript and gave approval for submission.

\section{Disclosure}

This manuscript was prepared according to the International Society for Medical Publication Professionals' "Good Publication Practice for Communicating CompanySponsored Medical Research: The GPP2 Guidelines." Funding to support the preparation of this manuscript was provided to MedVal by Eisai Inc. MLA received an honorarium for consultation sponsored by Eisai Inc on one occasion in the past 2 years. JB has received honoraria for consultation from an organization sponsored by Eisai Inc on one occasion in the past 2 years.

\section{References}

1. Wickham R. Best practice management of CINV in oncology patients: II. Antiemetic guidelines and rationale for use. J Support Oncol. 2010; 8(2 Suppl 1):10-15.
2. de Boer-Dennert M, de Wit R, Schmitz PI, et al. Patient perceptions of the side-effects of chemotherapy: the influence of $5 \mathrm{HT}_{3}$ antagonists. Br J Cancer. 1997;76(8):1055-1061.

3. Carelle N, Piotto E, Bellanger A, Germanaud J, Thuillier A, Khayat D. Changing patient perceptions of the side effects of cancer chemotherapy. Cancer. 2002;95(1):155-163.

4. Russo S, Cinausero M, Gerratana L, et al. Factors affecting patient's perception of anticancer treatments side-effects: an observational study. Expert Opin Drug Saf. 2014;13(2):139-150.

5. Sun CC, Bodurka DC, Weaver CB, et al. Rankings and symptom assessments of side effects from chemotherapy: insights from experienced patients with ovarian cancer. Support Care Cancer. 2005;13(4):219-227.

6. Grunberg SM. Chemotherapy-induced nausea and vomiting incidence and prevalence. Am Soc Clin Oncol Educ Book. 2012;32:541-543.

7. Grunberg SM, Deuson RR, Mavros P, et al. Incidence of chemotherapy-induced nausea and emesis after modern antiemetics. Cancer. 2004;100(10):2261-2268.

8. Cohen L, de Moor CA, Eisenberg P, Ming EE, Hu H. Chemotherapy-induced nausea and vomiting: incidence and impact on patient quality of life at community oncology settings. Support Care Cancer. 2007;15(5):497-503.

9. Hilarius DL, Kloeg PH, van der Wall E, van den Heuvel JJ, Gundy CM, Aaronson NK. Chemotherapy-induced nausea and vomiting in daily clinical practice: a community hospital-based study. Support Care Cancer. 2012;20(1):107-117.

10. National Comprehensive Cancer Network. NCCN Clinical Practice Guidelines in Oncology (NCCN Guidelines $\left.{ }^{\circledR}\right)$ : antiemesis. Version 1. 2014. Fort Washington, PA, USA: National Comprehensive Cancer Network; August 19, 2013. Available from: http://www.nccn.org/ professionals/physician_gls/f_guidelines.asp. Accessed July 11, 2014.

11. Farrell C, Brearley SG, Pilling M, Molassiotis A. The impact of chemotherapy-related nausea on patients' nutritional status, psychological distress and quality of life. Support Care Cancer. 2013;21(1): 59-66.

12. Grunberg SM, Warr D, Gralla RJ, et al. Evaluation of new antiemetic agents and definition of antineoplastic agent emetogenicity - state of the art. Support Care Cancer. 2011;19 Suppl 1:S43-S47.

13. Gralla RJ, Roila F, Tonato M, Herrstedt J. MASCC/ESMO antiemetic guideline 2013. Available from: http://mascc.memberclicks.net/ assets/documents/mascc_guidelines_english_2013.pdf. Accessed September 6, 2013.

14. Basch E, Prestrud AA, Hesketh PJ, et al. Antiemetics: American Society of Clinical Oncology clinical practice guideline update. J Clin Oncol. 2011;29(31):4189-4198.

15. Aapro M, Molassiotis A, Dicato M, et al. The effect of guideline-consistent antiemetic therapy on chemotherapy-induced nausea and vomiting (CINV): the Pan European Emesis Registry (PEER). Ann Oncol. 2012;23(8):1986-1992.

16. Navari RM. Management of chemotherapy-induced nausea and vomiting: focus on newer agents and new uses for older agents. Drugs. 2013;73(3):249-262

17. Hesketh PJ. Comparative review of 5-HT3 receptor antagonists in the treatment of acute chemotherapy-induced nausea and vomiting. Cancer Invest. 2000;18(2):163-173.

18. Roila F, Warr D, Clark-Snow RA, et al. Delayed emesis: moderately emetogenic chemotherapy. Support Care Cancer. 2005;13(2): 104-108.

19. Geling O, Eichler HG. Should 5-hydroxytryptamine-3 receptor antagonists be administered beyond 24 hours after chemotherapy to prevent delayed emesis? Systematic re-evaluation of clinical evidence and drug cost implications. J Clin Oncol. 2005;23(6):1289-1294.

20. Hickok JT, Roscoe JA, Morrow GR, et al. 5-Hydroxytryptaminereceptor antagonists versus prochlorperazine for control of delayed nausea caused by doxorubicin: a URCC CCOP randomised controlled trial. Lancet Oncol. 2005;6(10):765-772. 
21. Saito M, Aogi K, Sekine I, et al. Palonosetron plus dexamethasone versus granisetron plus dexamethasone for prevention of nausea and vomiting during chemotherapy: a double-blind, double-dummy, randomised, comparative phase III trial. Lancet Oncol. 2009;10(2): 115-124.

22. Gralla R, Lichinitser M, Van der Vegt S, et al. Palonosetron improves prevention of chemotherapy-induced nausea and vomiting following moderately emetogenic chemotherapy: results of a double-blind randomized phase III trial comparing single doses of palonosetron with ondansetron. Ann Oncol. 2003;14(10):1570-1577.

23. Eisenberg P, Figueroa-Vadillo J, Zamora R, et al. Improved prevention of moderately emetogenic chemotherapy-induced nausea and vomiting with palonosetron, a pharmacologically novel 5-HT3 receptor antagonist: results of a phase III, single-dose trial versus dolasetron. Cancer. 2003;98(11):2473-2482.

24. Aapro M, Grunberg S, Manikhas G, et al. A phase III, double-blind, randomized trial of palonosetron compared with ondansetron in preventing chemotherapy-induced nausea and vomiting following highly emetogenic chemotherapy. Ann Oncol. 2006;17(9): 1441-1449.

25. Hesketh PJ, Grunberg SM, Gralla RJ, et al. The oral neurokinin-1 antagonist aprepitant for the prevention of chemotherapy-induced nausea and vomiting: a multinational, randomized, double-blind, placebo-controlled trial in patients receiving high-dose cisplatin - the Aprepitant Protocol 052 Study Group. J Clin Oncol. 2003;21(22): 4112-4119.

26. Warr DG, Hesketh PJ, Gralla RJ, et al. Efficacy and tolerability of aprepitant for the prevention of chemotherapy-induced nausea and vomiting in patients with breast cancer after moderately emetogenic chemotherapy. J Clin Oncol. 2005;23(12):2822-2830.

27. Warr DG, Grunberg SM, Gralla RJ, et al. The oral $\mathrm{NK}_{1}$ antagonist aprepitant for the prevention of acute and delayed chemotherapy-induced nausea and vomiting: pooled data from 2 randomised, double-blind, placebo controlled trials. Eur J Cancer. 2005;41(9):1278-1285.

28. Dos Santos LV, Souza FH, Brunetto AT, Sasse AD, da Silveira Nogueira Lima JP. Neurokinin-1 receptor antagonists for chemotherapy-induced nausea and vomiting: a systematic review. J Natl Cancer Inst. 2012;104(17):1280-1292.

29. Jordan K, Gralla R, Jahn F, Molassiotis A. International antiemetic guidelines on chemotherapy induced nausea and vomiting (CINV): content and implementation in daily routine practice. Eur J Pharmacol. 2014;722:197-202.

30. Gilmore JW, Peacock NW, Gu A, et al. Antiemetic guideline consistency and incidence of chemotherapy-induced nausea and vomiting in US community oncology practice: INSPIRE study. J Oncol Pract. 2014;10(1):68-74.

31. Bloechl-Daum B, Deuson RR, Mavros P, Hansen M, Herrstedt J. Delayed nausea and vomiting continue to reduce patients' quality of life after highly and moderately emetogenic chemotherapy despite antiemetic treatment. J Clin Oncol. 2006;24(27):4472-4478.

32. Hesketh PJ, Van BS, Aapro M, et al. Differential involvement of neurotransmitters through the time course of cisplatin-induced emesis as revealed by therapy with specific receptor antagonists. Eur J Cancer. 2003;39(8):1074-1080.

33. Grunberg SM. Obstacles to the implementation of antiemetic guidelines. J Natl Compr Cancer Network. 2009;7(5):601-605.

34. Salsman JM, Grunberg SM, Beaumont JL, et al. Communicating about chemotherapy-induced nausea and vomiting: a comparison of patient and provider perspectives. J Natl Compr Cancer Network. 2012;10(2):149-157.

35. Cabana MD, Rand CS, Powe NR, et al. Why don't physicians follow clinical practice guidelines? A framework for improvement. JAMA. 1999;282(15):1458-1465

36. Navari RM. Prevention of emesis from multiple-day and high-dose chemotherapy regimens. J Natl Compr Cancer Network. 2007;5(1): 51-59.
37. Ellebaek E, Herrstedt J. Optimizing antiemetic therapy in multiple-day and multiple cycles of chemotherapy. Curr Opin Support Palliat Care. 2008;2(1):28-34.

38. Bremer K. A single-blind study of the efficacy and safety of intravenous granisetron compared with alizapride plus dexamethasone in the prophylaxis and control of emesis in patients receiving 5-day cytostatic therapy. The Granisetron Study Group. Eur J Cancer. 1992;28A(6-7):1018-1022.

39. Aapro M, Piguet D, Giger K, et al. The antiemetic efficacy and safety of granisetron compared with metoclopramide plus dexamethasone in patients receiving fractionated chemotherapy over 5 days. The Granisetron Study Group. J Cancer Res Clin Oncol. 1993;119(9): 555-559.

40. Rath U, Upadhyaya BK, Arechavala E, et al. Role of ondansetron plus dexamethasone in fractionated chemotherapy. Oncology. 1993;50(3):168-172.

41. Sledge GW Jr, Einhorn L, Nagy C, House K. Phase III double-blind comparison of intravenous ondansetron and metoclopramide as antiemetic therapy for patients receiving multiple-day cisplatin-based chemotherapy. Cancer. 1992;70(10):2524-2528.

42. Fox SM, Einhorn LH, Cox E, Powell N, Abdy A. Ondansetron versus ondansetron, dexamethasone, and chlorpromazine in the prevention of nausea and vomiting associated with multiple-day cisplatin chemotherapy. J Clin Oncol. 1993;11(12):2391-2395.

43. Handberg J, Wessel V, Larsen L, Herrstedt J, Hansen HH. Randomized, double-blind comparison of granisetron versus granisetron plus prednisolone as antiemetic prophylaxis during multipleday cisplatin-based chemotherapy. Support Care Cancer. 1998;6(1): 63-67.

44. Fauser AA, Pizzocaro G, Schueller J, Khayat D, Wilkinson P. A doubleblind, randomised, parallel study comparing intravenous dolasetron plus dexamethasone and intravenous dolasetron alone for the management of fractionated cisplatin-related nausea and vomiting. Support Care Cancer. 2000;8(1):49-54.

45. Noble A, Bremer K, Goedhals L, Cupissol D, Dilly SG. A double-blind, randomised, crossover comparison of granisetron and ondansetron in 5-day fractionated chemotherapy: assessment of efficacy, safety and patient preference. The Granisetron Study Group. Eur J Cancer. 1994;30A(8):1083-1088.

46. Forni C, Ferrari S, Loro L, et al. Granisetron, tropisetron, and ondansetron in the prevention of acute emesis induced by a combination of cisplatin-Adriamycin and by high-dose ifosfamide delivered in multiple-day continuous infusions. Support Care Cancer. 2000;8(2): 131-133.

47. Einhorn LH, Brames MJ, Dreicer R, Nichols CR, Cullen MT Jr, Bubalo J. Palonosetron plus dexamethasone for prevention of chemotherapyinduced nausea and vomiting in patients receiving multiple-day cisplatin chemotherapy for germ cell cancer. Support Care Cancer. 2007;15(11):1293-1300.

48. Rozzi A, Nardoni C, Corona M, et al. Palonosetron for the prevention of chemotherapy-induced nausea and vomiting in glioblastoma patients treated with temozolomide: a phase II study. Support Care Cancer. 2011;19(5):697-701.

49. Lorusso V, Giampaglia M, Petrucelli L, Saracino V, Perrone T, Gnoni A. Antiemetic efficacy of single-dose palonosetron and dexamethasone in patients receiving multiple cycles of multiple day-based chemotherapy. Support Care Cancer. 2012;20(12):3241-3246.

50. Musso M, Scalone R, Bonanno V, et al. Palonosetron (Aloxi ${ }^{\circledR}$ ) and dexamethasone for the prevention of acute and delayed nausea and vomiting in patients receiving multiple-day chemotherapy. Support Care Cancer. 2009;17(2):205-209.

51. Jordan K, Kinitz I, Voigt W, Behlendorf T, Wolf HH, Schmoll HJ. Safety and efficacy of a triple antiemetic combination with the NK-1 antagonist aprepitant in highly and moderately emetogenic multiple-day chemotherapy. Eur J Cancer. 2009;45(7): 1184-1187. 
52. Gao HF, Liang Y, Zhou NN, Zhang DS, Wu HY. Aprepitant plus palonosetron and dexamethasone for prevention of chemotherapyinduced nausea and vomiting in patients receiving multiple-day cisplatin chemotherapy. Intern Med J. 2013;43(1):73-76.

53. Olver IN, Grimison P, Chatfield M, et al. Results of a 7-day aprepitant schedule for the prevention of nausea and vomiting in 5-day cisplatin-based germ cell tumor chemotherapy. Support Care Cancer. 2013;21(6):1561-1568.

54. Hamada S, Hinotsu S, Kawai K, et al. Antiemetic efficacy and safety of a combination of palonosetron, aprepitant, and dexamethasone in patients with testicular germ cell tumor receiving 5-day cisplatin-based combination chemotherapy. Support Care Cancer. 2014;22(8):2161-2166.

55. Albany C, Brames MJ, Fausel C, Johnson CS, Picus J, Einhorn LH. Randomized, double-blind, placebo-controlled, phase III crossover study evaluating the oral neurokinin-1 antagonist aprepitant in combination with a 5HT3 receptor antagonist and dexamethasone in patients with germ cell tumors receiving 5-day cisplatin combination chemotherapy regimens: a Hoosier Oncology Group Study. J Clin Oncol. 2012;30(32):3998-4003.

56. Aloxi ${ }^{\circledR}$ (palonosetron $\mathrm{HCl}$ ) injection [prescribing information] Woodcliff Lake, NJ, USA: Eisai Inc.; Jul 2013.

57. Rojas C, Slusher BS. Pharmacological mechanisms of 5-HT 3 and tachykinin $\mathrm{NK}_{1}$ receptor antagonism to prevent chemotherapy-induced nausea and vomiting. Eur J Pharmacol. 2012;684(1-3):1-7.

58. Navari RM. Palonosetron: a second generation 5-hydroxytryptamine 3 receptor antagonist. Exp Opin Drug Metab Toxicol. 2009;5(12): $1577-1586$.

59. Rojas C, Stathis M, Thomas AG, et al. Palonosetron exhibits unique molecular interactions with the 5-HT3 receptor. Anesth Analg. 2008;107(2):469-478.

60. Rojas C, Thomas AG, Alt J, et al. Palonosetron triggers 5-HT(3) receptor internalization and causes prolonged inhibition of receptor function. Eur J Pharmacol. 2010;626(2-3):193-199.

61. Rojas C, Li Y, Zhang J, et al. The antiemetic 5-HT3 receptor antagonist Palonosetron inhibits substance P-mediated responses in vitro and in vivo. J Pharmacol Exp Ther. 2010;335(2):362-368.

62. Botrel TE, Clark OA, Clark L, Paladini L, Faleiros E, Pegoretti B. Efficacy of palonosetron (PAL) compared to other serotonin inhibitors (5-HT3R) in preventing chemotherapy-induced nausea and vomiting (CINV) in patients receiving moderately or highly emetogenic (MoHE) treatment: systematic review and meta-analysis. Support Care Cancer. 2011;19(6):823-832

63. Schwartzberg L, Barbour SY, Morrow GR, Ballinari G, Thorn MD, Cox D. Pooled analysis of phase III clinical studies of palonosetron versus ondansetron, dolasetron, and granisetron in the prevention of chemotherapy-induced nausea and vomiting (CINV). Support Care Cancer. 2014;22(2):469-477.

64. Jin Y, Sun W, Gu D, Yang J, Xu Z, Chen J. Comparative efficacy and safety of palonosetron with the first 5-HT3 receptor antagonists for the chemotherapy-induced nausea and vomiting: a meta-analysis. Eur $J$ Cancer Care. 2013;22(1):41-50.

65. Likun Z, Xiang J, Yi B, Xin D, Tao ZL. A systematic review and meta-analysis of intravenous palonosetron in the prevention of chemotherapy-induced nausea and vomiting in adults. Oncologist. 2011;16(2):207-216
66. Yeh YC, Blouin GC, Reddy P. Evidence to support use of palonosetron over generic serotonin type 3-receptor antagonists for chemotherapyinduced nausea and vomiting. Am J Health Syst Pharm. 2014;71(6): 500-506.

67. Kolesar JM, Eickhoff J, Vermeulen LC. Serotonin type 3-receptor antagonists for chemotherapy-induced nausea and vomiting: therapeutically equivalent or meaningfully different? Am J Health Syst Pharm. 2014;71(6):507-510.

68. Stupp R, Mason WP, Van den Bent MJ, et al. Radiotherapy plus concomitant and adjuvant temozolomide for glioblastoma. $N \mathrm{Engl}$ J Med. 2005;352(10):987-996.

69. Salvo N, Barnes E, van Draanen J, et al. Prophylaxis and management of acute radiation-induced skin reactions: a systematic review of the literature. Curr Oncol. 2010;17(4):94-112.

70. Salvo N, Doble B, Khan L, et al. Prophylaxis of radiation-induced nausea and vomiting using 5-hydroxytryptamine-3 serotonin receptor antagonists: a systematic review of randomized trials. Int J Radiat Oncol Biol Phys. 2012;82(1):408-417.

71. Feinberg BA, Gilmore J, Haislip S, Gondesen T, Saleh MN, Lenz WH. Data-driven medical decision-making in managing chemotherapyinduced nausea and vomiting. Community Oncol. 2009;6: $62-67$.

72. Tina Shih YC, Xu Y, Elting LS. Costs of uncontrolled chemotherapyinduced nausea and vomiting among working-age cancer patients receiving highly or moderately emetogenic chemotherapy. Cancer. 2007;110(3):678-685.

73. Boccia RV, Gordan LN, Clark G, Howell JD, Grunberg SM. Efficacy and tolerability of transdermal granisetron for the control of chemotherapy-induced nausea and vomiting associated with moderately and highly emetogenic multi-day chemotherapy: a randomized, double-blind, phase III study. Support Care Cancer. 2011;19(10): 1609-1617.

74. Affronti ML, Schneider SM, Herndon JE II, Schlundt S, Friedman HS. Adherence to antiemetic guidelines in patients with malignant glioma: translating evidence into practice. Support Care Cancer. 2014;22(7):1897-1905.

75. Molassiotis A, Farrell C, Bourne K, Brearley SG, Pilling M. An exploratory study to clarify the cluster of symptoms predictive of chemotherapy-related nausea using random forest modeling. $J$ Pain Symptom Manage. 2012;44(5):692-703.

76. Navari RM, Einhorn LH, Loehrer PJ Sr, et al. A phase II trial of olanzapine, dexamethasone, and palonosetron for the prevention of chemotherapy-induced nausea and vomiting: a Hoosier Oncology Group study. Support Care Cancer. 2007;15(11):1285-1291.

77. Navari RM, Gray SE, Kerr AC. Olanzapine versus aprepitant for the prevention of chemotherapy-induced nausea and vomiting: a randomized phase III trial. J Support Oncol. 2011;9(5):188-195.

78. Howell J, Clark G, Yellowlees A, Gutierrez-Esteinou R. Efficacy, safety, and tolerability of transdermal granisetron patch for prevention of multiday chemotherapy-induced nausea and vomiting: Phase III trial results (Abstract). J Oncol Pharm Pract. 2009; 15(Suppl 2):7-8.
Cancer Management and Research

\section{Publish your work in this journal}

Cancer Management and Research is an international, peer-reviewed open access journal focusing on cancer research and the optimal use of preventative and integrated treatment interventions to achieve improved outcomes, enhanced survival and quality of life for the cancer patient. The journal welcomes original research, clinical \& epidemiological

\section{Dovepress}

studies, reviews \& evaluations, guidelines, expert opinion \& commentary, case reports \& extended reports. The manuscript management system is completely online and includes a very quick and fair peerreview system, which is all easy to use. Visit http://www.dovepress.com/ testimonials.php to read real quotes from published authors. 